\title{
Review of geosynthetic-reinforced pile- supported (GRPS) embankments - parametric study and design methods
}

\author{
R. Alsirawan ${ }^{1, *}$ \\ ${ }^{1}$ Széchenyi István University, Doctoral School of Multidisciplinary \\ Engineering Sciences \\ Egyetem tér 1, 9026 Győr, Hungary \\ *e-mail: rashad.seirawan@gmail.com
}

Submitted: 26/09/2020; Accepted: 03/12/2020; Available online: 14/12/2020

Abstract: Embankment construction on soft soil may result in excessive settlement, loss of bearing capacity, or sliding instability. However, geosynthetic-reinforced pile-supported (GRPS) embankments offer an effective technique to overcome the problems resulting from soft foundations soils. This paper presents a review of the most important parameters affecting the behaviour of GRPS embankments as well as design methods that estimate tensile forces in the geosynthetic layers and load efficiency. Results highlight the importance of using GRPS embankments, but also reveal the inconsistencies between design methods. Finally, general conclusions about the design and construction of GRPS systems are presented.

Keywords: geosynthetic-reinforced pile-supported embankments; tensile forces; load efficiency

\section{Introduction}

Embankments are a fast, inexpensive way to raise the grade of, highways and railways. However, their construction over soft soil with high compressibility and low shear strength, is a real challenge for geotechnical engineers. Nowadays this challenge is more urgent as a result of the shortage of available land for infrastructure and the location of urban centres along rivers and coastlines. Embankments on soft soils are possible through techniques such as: soft soil replacement, preloading, prefabricated vertical drains (PVDs), lightweight embankment materials, basal 
reinforcement using geosynthetics, conventional columns (stone columns, deep soil mixing, etc.), and geosynthetics-reinforced platform and piles (GRPS).

The last technique has been widely used over the last three decades because of its advantages such as short waiting period for pore pressure dissipation, reduction of differential settlements at the embankment surface, and the ability to provide uniform support over heterogeneous foundation soils.

The typical GRPS embankment consists of a piles network and load transfer platform (LTP) located above the pile heads, Fig.1a. This platform generally includes one or more layers of geosynthetics (geogrid or geotextiles) underlain by piles that penetrate into firm ground. GRPS embankment systems are best suited for high loads and/or thick soft soil. This paper presents a review of the most important parameters affecting behaviour of GRPS embankments.

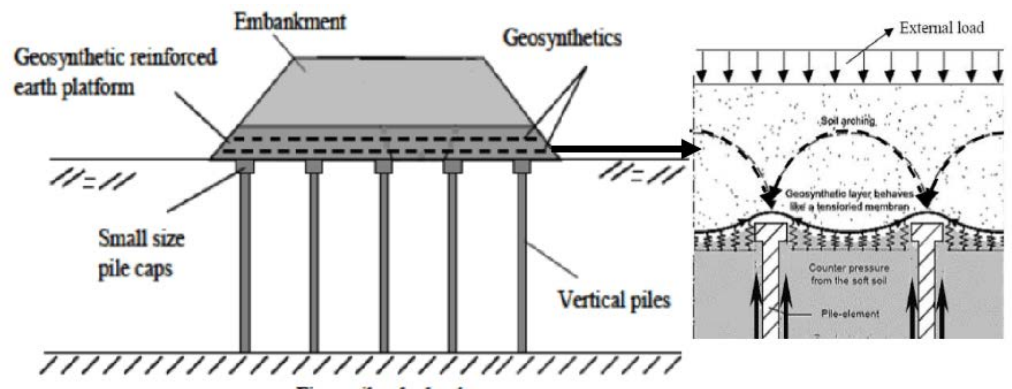

Firm soil or bedrock

(a)

(b)

Figure 1. GRPS embankment [1]

\section{Literature Review}

\subsection{The techniques of supporting embankments, an overview}

Since the load transfer mechanism between the embankment, geogrid, piles and foundation soils is very complex, empirical approaches have been used to assess the practical design parameters for this technique. The general belief is that load is transferred to the piles via soil arching, Fig.1b where the geogrid further enhances this effect. A well-designed GRPS will transfer loads to the piles and underlying firm layers, creating only a tolerable magnitude of differential settlement and an acceptable margin of safety against slope or bearing capacity failure within the embankment. The studies discussed below use a wide variety of assumptions and methods to evaluate the performance of GRPS systems. 
Sakleshpur and Madhav [1] described different techniques to support embankments on soft soil. These methods are:

1. Prefabricated vertical drains (PVDs): this technique is used to decrease the time required for soft soil to consolidate and strengthen itself.

2. Basal reinforcement with geosynthetics: this technique is used to increase the safety factor against failure through the tensile forces in the geosynthetics.

3. Stone columns: this technique is used in case of low loads to reduce the settlements and lateral deformations.

4. Piles: this technique is used over thick soft soil and/or high loads where the piles carry the major proportion of loads and that leads in turn to reduce the embankment surface settlements and soft soil settlement.

5. Piles with basal layers of geosynthetics: this technique is used to increase the proportion of loads carried by piles and thus decrease significantly the settlements.

Halder and Singh [2] explained the effect of using piles with one layer of geogrid, and found that the settlement and vertical stress applied on soft soil decrease about $65 \%$ relative to those without piles and geogrid. The lateral displacement at $1 \mathrm{~m}$ distance from the embankment toe decreases around $250 \%$, which make the stability of the embankment in a safe side.

Liu and Rowe [3] compared different improvement options of the embankments (one unimproved, one with piles, one with piles and one layer of geogrid, one with piles and two layers of geogrid). According to this study, the settlements at the embankment surface after using the improvement options decreased to $(60 \%, 41 \%$, and $38 \%$ ) respectively and the settlements at the soft soil surface decreased to (52\%, $31 \%$, and 28\%) respectively. Inserting the first geosynthetic layer reduces the settlement about $20 \%$ while the effect of the second layer is very low.

\subsection{Parametric study}

Before starting the parametric study, some indicators using to evaluate the soil arching phenomenon must be defined:

$>$ The soil arching ratio is defined as the ratio of the vertical stress applied on the soft soil between piles to the vertical stress resulting from the weight of embankment and surcharge.

$$
\rho=\frac{\sigma_{s}}{\gamma H+q}
$$

where $\sigma_{s}$ is the vertical stress on the soft soil, $\gamma$ is the embankment fill unit weight, $H$ is the embankment height, $q$ is the uniform surcharge. 
The stress concentration ratio is defined as the ratio of the vertical stress applied on the piles to the stress applied on the soft soil.

$$
S C R=\frac{\sigma_{p}}{\sigma_{s}}
$$

where $\sigma_{p}$ is the vertical stress on the pile head.

$>$ The cover rate is a ratio of the piles area (or pile caps area) to the area of the load transfer platform.

$>$ The load efficiency is a ratio of the vertical stress applied on the pile to the vertical stress resulting from the embankment weight and uniform surcharge.

$$
E=\frac{\sigma_{p}}{(\gamma H+q)}
$$

Han et al. [4] conducted a numerical study to examine the effect of several parameters on the performance of GRPS:

1. The number and stiffness of the geosynthetic layers.

2. The elastic moduli of deep-mixed columns and soft soil.

3. The pile spacing.

Their study demonstrated that inserting one geosynthetic layer in the platform decreased the maximum and differential settlements at the embankment surface (considering the settlement is the main problem of embankments on the soft soil) while the effect of more layers can be neglected. The geosynthetic stiffness was considered effective in reducing the settlements up to $4000 \mathrm{kN} / \mathrm{m}$ and after this value, the influence is not increase. The study also demonstrated that increasing the elastic moduli of piles and soft soil reduces both maximum and differential settlements, while the pile spacing has opposite effect.

Han and Gabr [5] conducted a numerical study on a GRPS embankment. The results showed that the soil arching ratio decreases with the increase of elastic modulus of piles. The stress concentration ratio increases with increasing the pile elastic modulus, embankment height, and geosynthetic stiffness.

Rathmayer [6] recommended using fill materials with good quality to decrease the cover rate. Han [7] found that the cover rate decreases to low values (around 40\%) and ranging from $10 \%$ to $20 \%$ in the case of using geosynthetics reinforcement. Nuñez et al. [8] chose cement-treated fill instead of granular fill to use in the load transfer platform to find its effect on the load efficiency. The researchers found that the load efficiency increases by about $85 \%$ for the embankments with little height, less than $1.5 \mathrm{~m}$. 
In the study described in Chevalier et al [9], a numerical method was used to understand the mechanism of load transfer through the granular platform. The results showed that the peak friction angle and thickness $h_{m}$ of the platform play a main role in redirecting the load toward the piles. Fig. $2 a$ shows that the load efficiency increases with increasing the platform thickness, $q_{t}$ is defined as stress equivalent to the total load applied on the soft soil. The results in Fig. 2b show that the maximum settlement $\delta$ of the soft soil reduces when the platform thickness changes from 0.5 $\mathrm{m}$ to $1.0 \mathrm{~m}$. Add to that, the inclusion of one layer of geosynthetic will lower this value further.

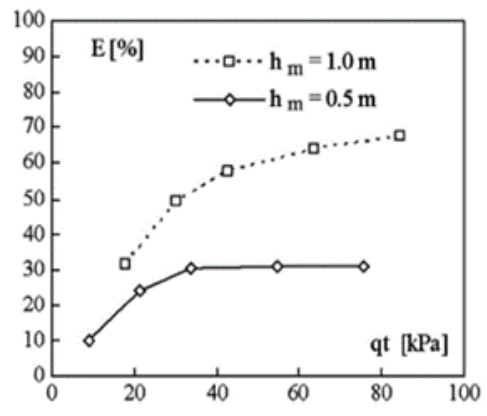

(a)

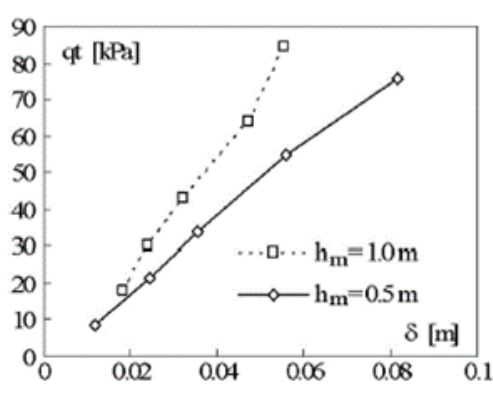

(b)

Figure2. The influence of platform thickness on (a) load efficiency, (b) maximum settlement of soft soil [9]

In order to evaluate the most important parameters affecting GRPS behaviour, van Eekelen et al [10][11][12] carried out an extensive parametric study by conducting an experiment program that included twelve tests. The results were as follows:

1. The load efficiency increases (as a percentage) as the uniform surcharge increases

2. The use of granular fill $\left(\varnothing=49^{\circ}\right)$ instead of sand fill $\left(\varnothing=40.88^{\circ}\right)$ in the platform increases the load efficiency.

3. The maximum strains can be observed on the pile head and in the strip between two piles.

4. The vertical deflections of the geosynthetic are approximately the same in the case of using a geogrid or a geotextile.

5. The use of one biaxial layer or two uniaxial layers located above each other gives the same influence.

6. Inclusion one layer of the geosynthetic gives a relatively larger value of the load efficiency in comparison with using two layers apart. 
Other researchers have supported the results obtained and demonstrated the effect of other parameters on the behavior of GRPS embankments:

Load efficiency is influenced by a host of parameters and increases with the uniform surcharge increases and with the use of high-quality fill material in the platform [13], and this is consistent with van Eekelen's results. Fagundes et al. [14] conducted a series of centrifuge tests. The results showed that the load efficiency reaches $100 \%$ in all the tests. Fig. 3 shows that the load efficiency increases with the settlement of soft soil $\Delta \mathrm{w}$ and the maximum deflection of the geosynthetic between two piles $y_{d}$. The maximum deflection of the geosynthetic $y_{d}$ relies on the clear spacing between two piles (s-a), embankment thickness, and geosynthetics stiffness. While it is impossible to reach $100 \%$ efficiency without the geosynthetic layers.

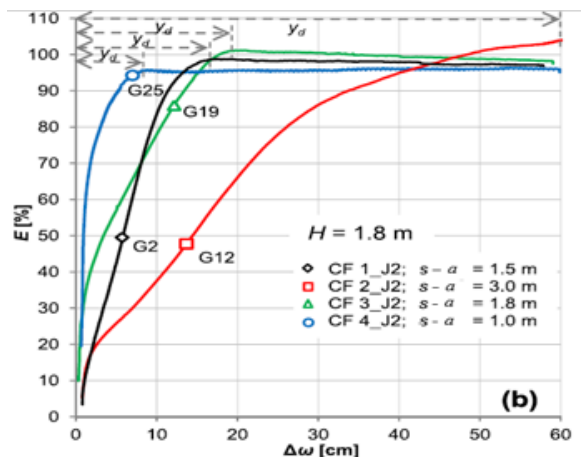

Figure3. Load efficiency versus settlements of soft soil [14]

The differential settlement at the embankment surface decreases as the embankment height increases, pile spacing decreases, and geosynthetic stiffness increases. The minimum embankment height to prevent the settlements equal to 2.1 (s-a) and the embankment height should be greater than 2.5 the height of a soil arch to avoid the differential settlements [14]. Al-Ani and based on a laboratory test model found that the settlement of the soft soil reduces when fill material with high effective friction angle is used while the effect of dilatancy angle $(\Psi)$ on the soft soil settlements is small in comparison with that of effective friction angle [13]. Phutthananon et al. [15] have performed three physical model tests to investigate the effect of the pile cap size, pile strength, and thickness of soft soil on the differential settlements. The results indicated that enlarging the pile cap plays an important role in decreasing the differential settlements at the embankment surface. The results also indicated that the soft soil thickness has a little impact on the differential settlement but a significant impact on the maximum settlement, and the lower strength of the pile with small cap size leads to decrease differential settlement while has a negative influence on the maximum settlement. Thanh Truc et al. [16] carried out two- 
dimensional and three-dimensional analyses by Plaxis 2-D and Plaxis 3-D to understand the behavior of GRPS embankment. They found that the differential settlements at the embankment base (over pile heads and in midpoints) are approximately the same under low surcharge values for low embankment heights, these settlements increase as the pile spacing increases; The analyses gave different results where Plaxis 2-D gave the largest values.

\subsection{Design methods of GRPS embankments}

The design of GRPS embankments is complicated due to different soil-structure interactions in this system. There are several empirical methods for the design focus on the load efficiency and tension in the geosynthetic layers. This paper addresses one side of the design related to tensile forces in the geosynthetics layers.

\subsubsection{Terzaghi’s design method (1943)}

Terzaghi [17] presented soil arching theory based on a trap door experiment. This phenomenon occurs when one part of soil moves downward while another part remains in its place and shear forces are generated on the sliding surfaces between two parts of the soil. Fig. 4 shows soil Arching analysis with Terzaghi's method, the shearing resistance is given by the following equation:

$$
\tau=c+\sigma \tan \varnothing
$$

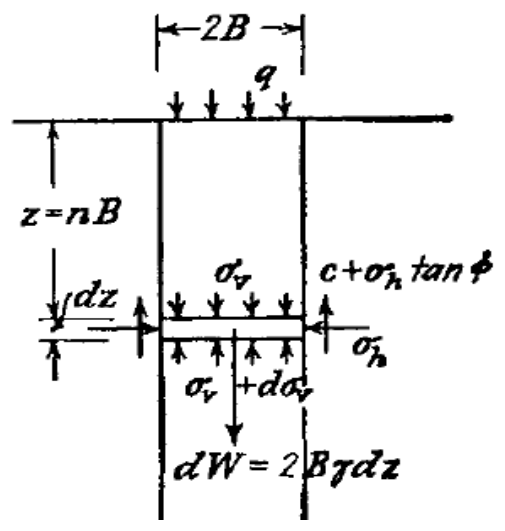

Figure 4. Soil arching phenomenon [17]

The requirement of equilibrium:

$$
2 B \gamma d z=2 B\left(\sigma_{v}+d \sigma_{v}\right)-2 B \sigma_{v}+2 c d z+2 K_{0} \sigma_{v} d z \tan \emptyset
$$

Or 


$$
\frac{d \sigma_{v}}{d z}=\gamma-\frac{c}{B}-K_{0} \sigma_{v} \frac{\tan \emptyset}{B}
$$

where $\tau$ is the shear stress, $\sigma$ is the vertical stress, c, $\varnothing$ are friction angle and cohesion of the soil, 2B is the width of a trap door, $\gamma$ is the soil unit weight, $\sigma_{v}$ is the vertical stress, $K_{0}=\sigma_{h} / \sigma_{v}$ is the earth pressure coefficient at rest, $q$ is the uniform surcharge.

The solution to these equations is of the form:

$$
\sigma_{v}=\frac{B(\gamma-c / B)}{K_{0} \tan \emptyset}\left(1-e^{-K_{0} \tan \emptyset z / B}\right)+q e^{-K_{0} \tan \emptyset z / B}
$$

Russell and Pierpoint (1997) [18], using Terzaghi's analysis, described the arching phenomenon in a piled embankment. They calculate the tension in the geosynthetic as follows:

$$
T=\frac{s_{3 D} \gamma H\left(s^{2}-a^{2}\right)}{4 a} \sqrt{1+\frac{1}{6 \varepsilon}}
$$

where $a$ is the pile cap width, $s$ is the pile spacing, $\varepsilon$ is the initial strain to generate tensile load and equal to $5 \%, S_{3 D}$ is the stress reduction ratio and given by:

$$
S_{3 D}=\frac{\left(\mathrm{s}^{2}-\mathrm{a}^{2}\right)}{4 H a K_{0} \tan \emptyset}\left(1-e^{\frac{-4 H a K_{0} \tan \emptyset}{\left(\mathrm{s}^{2}-\mathrm{a}^{2}\right)}}\right)
$$

where $H$ is the embankment height.

2.3.2. Guido et al. design method (1987)

Guido et al. [19] have performed plate-loading tests and found that the load spreads in the load transfer platform at an angle of $45^{\circ}$ from the LTP base in twodimensional plane-strain condition. This method assumed that the geosynthetic layers and piles carried the full load while the soft soil does not carry any proportion of the load.

The geosynthetic tension is calculated as follow:

$$
\begin{aligned}
& T=\frac{W}{2 \sin \delta} \\
& W=0.525(\gamma H+q)
\end{aligned}
$$

where $W$ is the load acting on geosynthetic, $\delta$ is the angle friction between soil and geosynthetic. 


\subsubsection{Carlson design method (1987)}

Carlson [20] suggested a method to calculate the load resulting from the soil wedge which applied on the geosynthetic as shown in Fig. $5 a$.

Assumptions of the Carlson method include: the apex angle of the soil wedge is $30^{\circ}$, the soil wedge represents the area (A) between two piles and not the area (B) as shown in Fig. 5b, this is considered nonconservative and leads to underestimate the tensile forces.

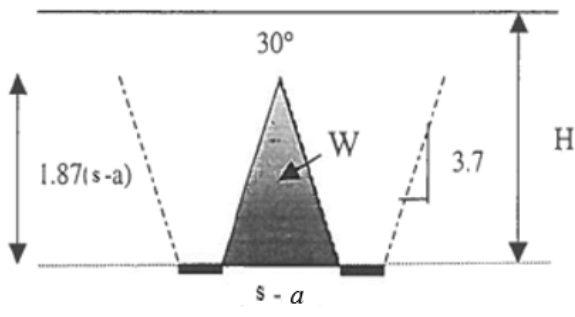

(a)

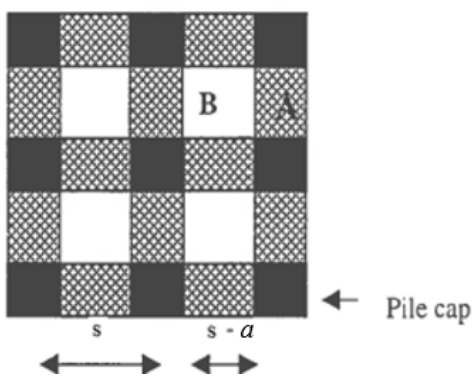

(b)

Figure 5. (a) Soil wedge, (b) A and B areas according to Carlson method [21].

They used equation (12) to calculate the weight of soil wedge:

$$
W=\frac{(s-a)^{2}}{4 \tan 15^{\circ}} \gamma
$$

Due to the applied load, the geosynthetic begins to deflect, and as a result, the strain $\varepsilon$ increases as shown in Fig. 6. The geosynthetic deflection is given as follows:

$$
d=(s-a) \sqrt{\frac{3}{8} \varepsilon}
$$

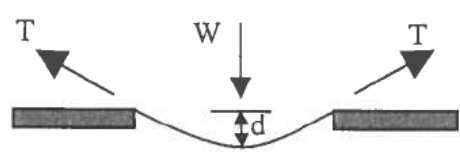

Figure 6. Deflection of geosynthetic [21]

The geosynthetic tension is given by the following equation:

$$
T=\frac{(s-a)^{3}}{16 \tan 15^{\circ}} \gamma \frac{1}{2 d} \sqrt{1+\frac{16 d^{2}}{(s-a)^{2}}}=W \frac{s-a}{8 d} \sqrt{1+\frac{16 d^{2}}{(s-a)^{2}}}
$$




\subsubsection{Hewlett and Randolph design method (1988)}

Hewlett and Randolph [22] [23] suggested that the proportion of the load is transferred to the pile heads as a form of hemispherical domes, and the rest is carried by the geosynthetic layer. This method supposed that the system may fail at the arch top (i.e. efficiency Ev) or at the pile heads (i.e. efficiency ET) as shown in Fig. 7. After determining the minimum efficiency between both of them, the maximum load carried by the geosynthetic is determined. In general, for the large embankment height, the efficiency at the pile heads is dominant, while for small embankment height, the efficiency at the top of the arch is dominant.

-Arching efficiency at the arch top [23]:

$$
E_{V}=1-\left[1-\left(\frac{a}{s}\right)^{2}\right](A-A B+C)
$$

where:

$$
\begin{aligned}
& A=\left[1-\left(\frac{a}{s}\right)\right]^{-2\left(K_{P}-1\right)} \\
& B=\frac{s}{\sqrt{2} H}\left[\frac{2 K_{P}-2}{2 K_{P}-3}\right] \\
& C=\frac{s-a}{\sqrt{2} H}\left[\frac{2 K_{P}-2}{2 K_{P}-3}\right]
\end{aligned}
$$

where, $K_{P}$ is the passive earth pressure coefficient [23]:

$$
K_{P}=\frac{1+\sin \varnothing}{1-\sin \emptyset}
$$

- Arching efficiency at the level of pile heads can be calculated by following equation [24]:

$$
E_{T}=\frac{\beta}{1+\beta}
$$

where $\beta$ is a coefficient is given as follows [23]:

$$
\beta=\frac{2 K_{P}}{\left(2 K_{P}+1\right)\left(1+\left(\frac{a}{s}\right)\right)}\left[\left(1-\frac{a}{s}\right)^{-K_{P}}-\left(1+K_{P} \frac{a}{s}\right]\right.
$$

The proportion of the load applied on the geosynthetic between adjacent piles is given as follows [23]: 


$$
\sigma_{v, g e o}=\frac{s^{2}}{s^{2}-a^{2}} \sigma_{v}\left(1-E_{\min }\right)
$$

with

$$
\sigma_{v}=\gamma_{\gamma} \gamma_{r} H+\gamma_{G} g+\gamma_{Q} q
$$

where $\gamma_{\gamma}$ is the partial factor on the soil unit weight, $\gamma_{r}$ is the embankment unit weight, $\gamma_{G}$ is the partial factor on the permanent actions, $g$ is the permanent excess vertical load, $\gamma_{Q}$ is the partial factor on the variable actions, $q$ is the variable excess vertical load, $E_{\text {min }}$ : is the minimum of $E_{V}$ and $E_{T}$

British Standard BS8006 (2010) [24] used Hewlett and Randolph method to calculate the geosynthetic tension (per lineal meter) by the following equation:

$$
T=\frac{(s-a) s \sigma_{v, g e o}}{a}\left(1+\frac{1}{6 \varepsilon}\right)^{0.5}
$$

\subsubsection{Low et al. design method (1994)}

Low et al. [26] developed Hewlett and Randolph method to investigate the arching phenomena in GRPS embankment where this method assumed semi-cylindrical sand arches are formed between pile walls. According to this method, cap-pile and geotextile contribute to decreasing embankment surface differential settlement. Low et al. developed charts and equations to estimate the strain and tension in the geosynthetic layers and the vertical stress applied on the soft soil. The results showed a partial agreement between theoretical and experimental analyses.
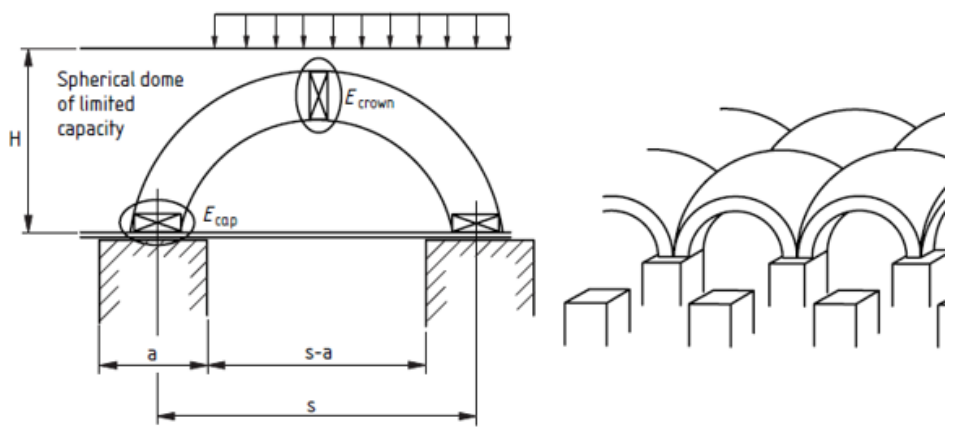

Figure 7. Soil arching according to Hewlett and Randolph [25]

The tension in the geosynthetics can be calculated by the following equation [27]:

$$
T=J \varepsilon
$$

where $J$ is the tensile stiffness of geosynthetic, $\varepsilon$ is the axial strain and given by: 


$$
\varepsilon=\frac{\theta-\sin \theta}{\sin \theta}
$$

where $\theta$ is the half the subtended angle of the geosynthetics arc after deformation and given by:

$$
\sin \theta=\frac{4\left(\frac{t}{s-a}\right)}{1+4\left(\frac{t}{s-a}\right)^{2}}
$$

where $t$ is the maximum vertical displacement of soft soil in the midpoint between pile caps. The vertical stress applied on the soft soil in this point can be calculated as follows:

$$
\sigma_{s}=\frac{\gamma(s-a)\left(K_{P}-1\right)}{2\left(K_{P}-2\right)}+\left(\frac{s-a}{s}\right)^{K_{P}-1}\left[\gamma H-\frac{\gamma s}{2}\left(1+\frac{1}{K_{P}-1}\right]\right.
$$

Because of difficulty in finding the maximum displacement $t$, the appropriate solution is the reliance on the equilibrium of the vertical forces

$$
\begin{aligned}
& T / R=\sigma_{s}-\frac{t E_{c}}{D} \\
& R=\frac{s-a}{2 \sin \theta}
\end{aligned}
$$

where $E_{c}$ is the soft soil elastic modulus, $D$ is the soft soil depth. Low et al. suggested using trial values of maximum displacement $t$ to fulfil the equilibrium of vertical forces.

\subsubsection{British Standards BS8006 design method (1995)}

This method [25] relied on a variety of analytical, numerical, and physical models to understand the mechanism of load transferring through the load transfer platform to the pile caps. Marston (1913) presented the following equation to describe the ratio of vertical stress carried by piles to the vertical stress exerted on the embankment base:

$$
\frac{P_{c}^{\prime}}{\sigma_{v}^{\prime}}=\left[\frac{C_{c} a}{H}\right]^{2}
$$

where $P_{c}^{\prime}$ is the vertical stress applied on the pile caps, $\sigma_{v}^{\prime}$ is the vertical stress at the embankment base and equal to $f_{f s} \gamma H+f_{q} q,\left(f_{f s}=1.3\right.$ the partial factor for soil unit weight, $f_{q}=1.3$ partial factor for surcharge load), $\gamma$ is the unit weight of the 
embankment fill, $q$ is the uniform surcharge, $C_{c}$ is the arching coefficient $\left(C_{c}=\right.$ $1.95 \mathrm{H} / \mathrm{a}-0.18$ for end bearing piles, $C_{c}=1.5 \mathrm{H} / \mathrm{a}-0.07$ for frictional piles.

The vertical load carried by geosynthetic between piles is calculated from:

For $H \geq 1.4(s-a)$;

$$
W=\frac{1.4 s f_{f s} \gamma(s-a)}{\left(s^{2}-a^{2}\right)}\left[s^{2}-a^{2}\left(\frac{P_{c}^{\prime}}{\sigma_{v}^{\prime}}\right)\right]
$$

For $0.7(s-a) \geq H \geq 1.4(s-a)$;

$$
W=\frac{s f_{f s} \gamma H+f_{q} q}{\left(s^{2}-a^{2}\right)}\left[s^{2}-a^{2}\left(\frac{P_{c}^{\prime}}{\sigma_{v}^{\prime}}\right)\right]
$$

The tension in the geosynthetic for each lineal meter can be calculated by the following equation:

$$
T=0.5 W \frac{s-a}{a}\left(1+\frac{1}{6 \varepsilon}\right)^{0.5}
$$

where the initial strain $\varepsilon=6 \%$.

Van Eekelen et al. [28] proposed that BS8006 designs a strong geosynthetic resulting in an expensive solution, and modified the load carried by geosynthetics. The results showed after comparison with the measurements that the modified BS8006 is more precise than BS8006.

\subsubsection{Swedish design method (2002)}

Rogbeck et al. [29] suggested that the vertical load, carried by geosynthetic, forms a pyramid of $75^{\circ}$ wall inclination and this is also acceptable even if the height of the embankment is lower than the pyramid top, i.e. $(s-a) / 2 \tan 15^{\circ}$ as shown in Fig. 8a.

Assumptions of Swedish method include: one layer of geosynthetic is used and its position should be within $0.1 \mathrm{~m}$ above pile heads, the geosynthetic is deformed under loading (the initial strain $\varepsilon=6 \%$ and strain at failure is less than $70 \%$ ). Cover rate $\geq 10 \%$ and the embankment height $H \geq(s-a)$.

The 2-D soil pyramid weight is calculated by the following equation:

$$
W=\frac{(s-a)^{2} \gamma}{4 \tan 15^{\circ}}
$$


The load is distributed over the surface with 3-D impacts as shown in Fig. 8b. the tension in the geosynthetic can be calculated for each lineal meter of depth by the following equation:

$$
T=0.5\left(1+\frac{s}{a}\right) W\left(1+\frac{1}{6 \varepsilon}\right)^{0.5}
$$

\subsubsection{Collin design method (2004)}

Collin et al. [29] recommended using a load transfer platform (LTP) under embankment with three layers of geosynthetic at least to create a stiffened beam.

Assumptions of Collin method include: the load transfer platform thickness $h \geq$ $(s-a)$. The distance between geosynthetic layers $h_{n} \geq 200 \mathrm{~mm}$. The initial strain in the geosynthetic $\varepsilon=5 \%$.

Fig. 9 shows the soil arching according to Collin method, where every layer of geosynthetic is subjected to a uniform vertical load from the soil wedge under the arch and can be calculated as follows:

$$
W_{n}=\frac{\left[(s-a)_{n}^{2}-(s-a)_{n+1}^{2}\right] h_{n} \gamma}{(s-a)_{n}^{2}}
$$

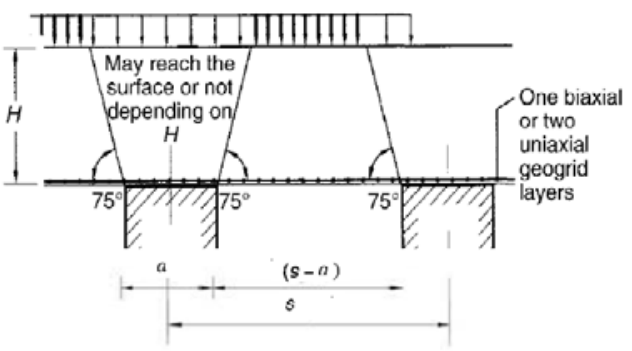

(a)

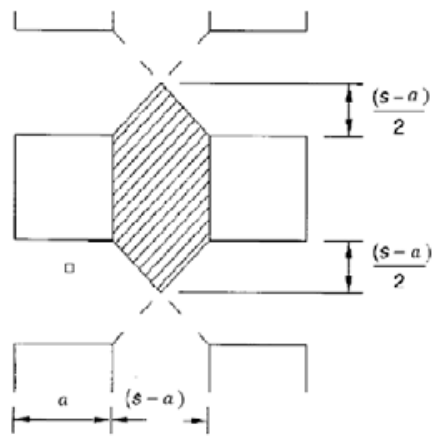

(b)

Figure 8. (a) Arching according to Swedish method, (b) load distribution between piles [29]

The tension in the geosynthetic is calculated as follows:

$$
T=\frac{W_{n} \Omega D}{2}
$$


where $\mathrm{D}$ is the design spanning for tension membrane and equal to $(s-a)_{n}, \Omega$ is the dimensionless factor and equal to 0.97 for geosynthetic strain $\varepsilon=5 \%$.

In 2005 Collin et al. modified this method by adding one layer of geosynthetic located directly above pile heads and this layer is designed as a catenary, the vertical load applied on this layer is given by:

$$
W_{n}=\frac{h_{n} \gamma}{3}
$$

The tension in the geosynthetic is calculated as follows:

$$
T=\frac{W_{n} \Omega D}{2}
$$

where $\mathrm{D}$ is the design span for tensioned membrane and equal to $1.41\{(s-a)-$ $2\left[\sum\right.$ vertical spacing $\left.\left./ \tan 45^{\circ}\right]\right\}, \Omega$ is the dimensionless factor.

\subsubsection{Kempfert et al. design method (2004)}

Kempfert et al. [30] [31] relied on tests of a three-dimensional model, this model consists of four piles were installed in peat soil with reinforced or unreinforced load transfer platform LTP, to investigate the bearing and deformation behaviour of the supported embankment. The design approach of this method depends on determining the loads applied on the piles and soft soil, then the tension in the geosynthetic is calculated to carry the load applied on the soft soil. This method considers the soft soil support. The geosynthetic tension is given as follows:

$$
T=J \varepsilon
$$

where $J$ is the geosynthetic stiffness, $\varepsilon$ is the maximum strain (the reference [31] to get more information on maximum strain)

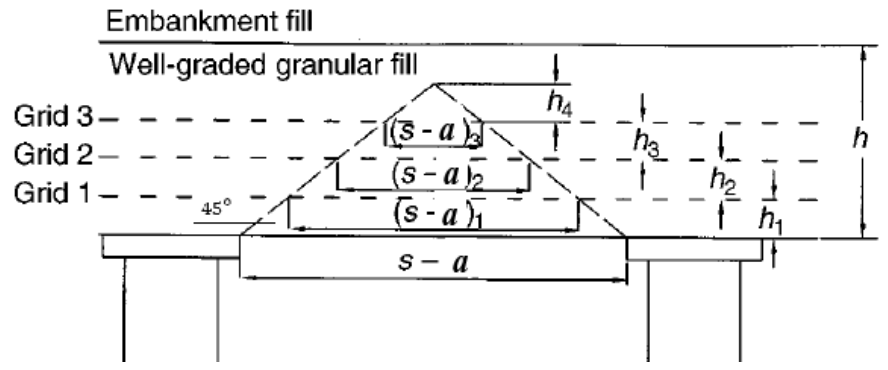

Figure 9. Soil arching according to Collin design method [29] 


\subsubsection{Abusharar et al. design method (2008)}

Abusharar et al. [32] modified Low et al. method by adding the effect of uniform surcharge $q$ on the embankment surface. In this method, the pile spacing is less than the embankment height and the vertical load is uniformly distributed on the geosynthetic as shown in Fig. 10a. The vertical stress applied on the middle of the soft soil between pile caps is given as follows:

$$
\sigma_{s}=\frac{\gamma(s-a)\left(K_{P}-1\right)}{2\left(K_{P}-2\right)}+\left(\frac{s-a}{s}\right)^{K_{P}-1}\left[q+\gamma H-\frac{\gamma s}{2}\left(1+\frac{1}{K_{P}-1}\right]\right.
$$

Fig. 10b shows a subtended angle $2 \theta$, radius of the geosynthetic arc after deformation, and maximum displacement at the middle of the soft soil $\mathrm{t}$.

The geosynthetic tension is calculated as follow:

$$
T=4 \beta^{2} J+0.25 s^{\prime} \lambda\left(\sigma_{s} \tan \emptyset+\frac{t E_{c}}{D} \tan \emptyset_{c}\right)
$$

where $\beta=\frac{t}{s^{\prime}}, s^{\prime}=(s-a), \lambda$ is the factor ranges between 0.7 and 0.9 (this value depends on the geosynthetic type), $\emptyset_{c}$ is the friction angle of soft soil. To solve equation (40), the first step is to find $\beta$ and then the maximum displacement $\mathrm{t}$ :

$$
a \beta^{3}+b \beta^{2}+c \beta+d=0
$$

where $a=32 D J+4 s^{\prime 2} E_{c}, b=2 s^{\prime 2} \lambda E_{c} \tan \emptyset_{c}-4 s^{\prime} D \sigma_{s}, c=2 s^{\prime} D \sigma_{s} \lambda \tan \emptyset+$ $s^{\prime 2} E_{c}, d=-s^{\prime} D \sigma_{s}$.

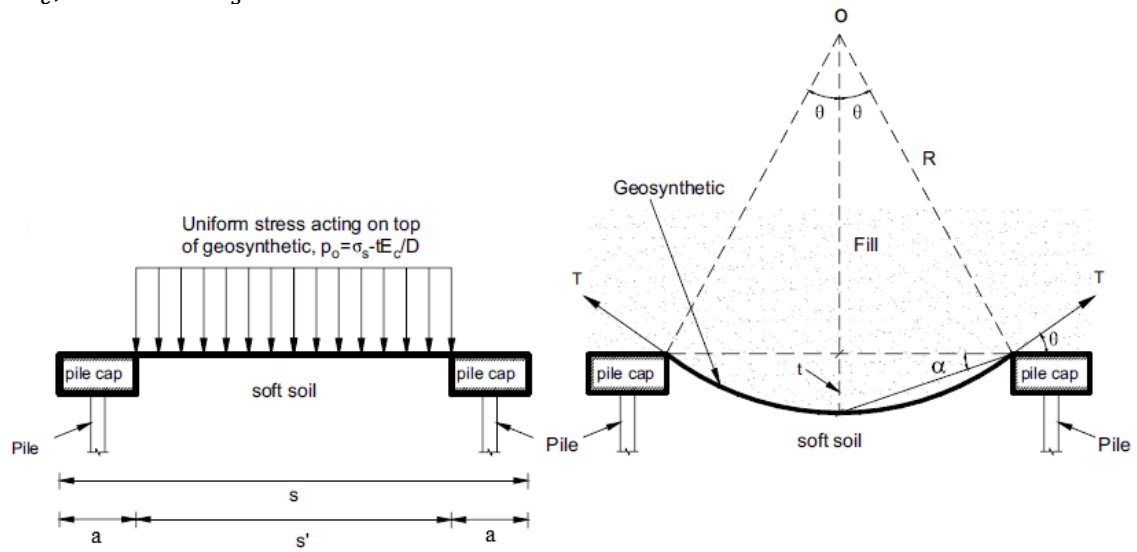

(a)

(b)

Figure 10. (a) Uniform stress acting on the geosynthetic, (b) deformed shape of geosynthetic [32] 


\section{Discussion}

The results obtained from the review demonstrated that GPRS embankment is an effective solution to overcome the problems resulting from the soft soil such as insufficient bearing capacity and large settlements, especially over soft soil with large thickness and/or in case of the high loads. The mechanism of transferring the load through the embankment to the piles is a soil-arching mechanism and due to that, it can be observed the concentration of stresses over the pile heads and that is related to the different between piles stiffness and soft soil stiffness. Generally, increasing the geosynthetic stiffness, elastic modulus of piles and soft soil, friction angle of the load transfer platform and cover rate contributes in reducing the maximum and differential settlements at the embankment surface, which is the main objective.

The presence of many design methods indicates a lack of understanding of the precise load transfer mechanism to the piles and soft soil. The researchers relied on numerical and experimental models to calculate the tensile forces and loads acting on geosynthetic layers. (These methods are more extensive, but this paper presents the equations used to calculate the applied load on geosynthetic and tensile forces) and none of them used a comprehensive model to design GRPS embankment, this led to a significant difference between the results as shown in Fig 11.

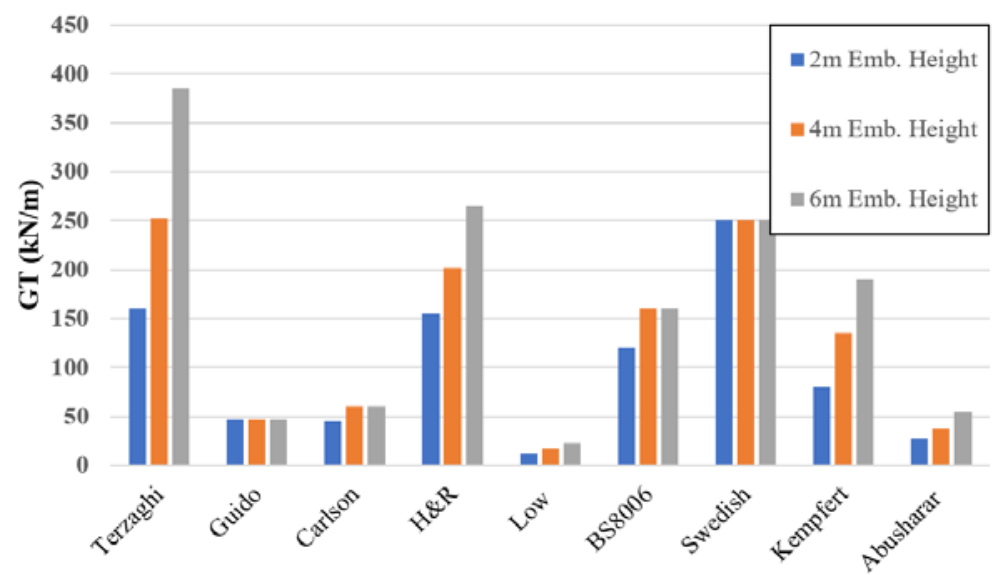

Figure 11. Geosynthetic tension according to design methods. 
The design methods used different physical models, and some of them will be mentioned:

1. Low used a two-dimensional model of GRPS embankment where add caps to piles in his model.

2. Hewlett and Randolph developed a three-dimensional unreinforced experimental model.

3. Kempfert used a three-dimensional model, this model consists of four piles were installed in peat soil with reinforced or unreinforced load transfer platform LTP.

The previous examples demonstrate the difference between the physical models. add to that, some parameters (e.g. elastic modulus of piles and, soft soil and LTP material properties, surcharge loads, position of the geosynthetic layer) are not included in all design methods. Table 1. highlights a set of differences between design methods, it does not cover all the differences, but rather the most important ones. The development of GRPS embankment numerical models makes it possible to include the influence of all parameters in the design. The results of numerical simulation are supposed to give results close to reality in comparing with the analytical methods.

Finally, there are many differences between the methods and this can be justified due to the lack of a comprehensive model and the failure to include the influence of all parameters in the calculations. The literature review demonstrated a significant difference between the results of calculated geosynthetic tensile forces according to these methods. 
Table 1. Differences between design methods, $G S^{*}$ : Geosynthetic, $(R \& P)^{* *}$ : Russell and Pierpoint calculated the tension in the geosynthetic using Terzaghi's analysis, $(J)^{* * *}$ : If the stiffness is taken into consideration when calculating $T$, : Angle of arch from horizontal (deg).

\begin{tabular}{|c|c|c|c|c|}
\hline $\begin{array}{l}\text { Design } \\
\text { Method }\end{array}$ & Soil arch shape & $\begin{array}{c}\text { GS* layer } \\
\text { number }\end{array}$ & $\begin{array}{c}\mathbf{G S}^{*} \text { stiffness } \\
(\mathbf{J})^{* * *}\end{array}$ & $\begin{array}{l}\text { Soft soil } \\
\text { support }\end{array}$ \\
\hline Terzaghi & Rectangle-2D & 1 layer $(\mathrm{R} \& \mathrm{P})^{* *}$ & No & No \\
\hline Guido & Triangle -2D $\left(45^{\circ}\right)^{a}$ & 1 layer & No & No \\
\hline Carlson & Triangle-2D $\left(75^{\circ}\right)^{a}$ & 1 layer & No & Yes \\
\hline $\begin{array}{l}\text { Hewllet and } \\
\text { Randolph }\end{array}$ & $\begin{array}{c}\text { hemispherical dome - } \\
\text { 3D } \\
\end{array}$ & 1 layer & No & No \\
\hline Low & semi-circle-2D & 1 layer & Yes & Yes \\
\hline BS8006 & semi-circle-2D & 1 layer & No & No \\
\hline Swedish & Pyramid-3D $\left(75^{\circ}\right)^{a}$ & 1 layer & No & No \\
\hline Collin & Pyramid-3D $\left(45^{\circ}\right)^{a}$ & $\geq 3$ layers & No & Yes \\
\hline Kempfert & $\begin{array}{l}\text { multi-shell domes with } \\
\text { different centres- 3D }\end{array}$ & 1 layer & Yes & Yes \\
\hline Abusharar & semi-circle -2D & 1 layer & Yes & Yes \\
\hline
\end{tabular}

\section{Conclusions}

The aim of this paper is conducting an overview of GRPS embankments, and the results can be summarized as follows:

$\checkmark$ The geosynthetic layers with piles network technique is used to support embankments over thick soft soil and/or high loads where it is difficult to use other techniques under these conditions. GPRS embankment is an effective solution to overcome the problems resulting from the soft soil such as insufficient bearing capacity and large settlements.

$\checkmark$ The load efficiency increases with increasing the platform thickness, geosynthetic stiffness, cover rate, and uniform surcharge, and decreasing the pile spacing. The load efficiency also increases by using fill material with good quality and using one geosynthetic layer.

$\checkmark$ The settlements at the embankment surface decrease with increasing the stiffness of piles and soft soil, geosynthetic stiffness, cover rate, and 
embankment thickness. Add to that, inserting the geosynthetic layers and using fill material with good quality decrease the settlements.

$\checkmark$ The design methods of GRPS embankments are generally used to calculate the tension in the geosynthetics, and the load efficiency.

$\checkmark \quad$ The design methods are similar in describing the mechanism of load transferring and differ in the soil arch shape, for example, Hewlett and Randolph supposed that the soil arch shape is semi-spherical; Abusharar et al., Low et al. and BS 8006 supposed that the shape of soil arch is a semi-cylindrical.

$\checkmark \quad$ Some methods considered the influence of soft soil such as Low et al. and Kempfert et al. while others neglected this influence such as Hewlett and Randolph and BS 8006. Some methods assumed inserting one geosynthetic layer in the load transfer platform to act as a catenary such as Swedish and BS8006 while others assumed using three layers to act as beam such as the Collin method.

$\checkmark$ The design methods give a significant difference between the results of calculated geosynthetic tensile forces due to the lack of a comprehensive model and the failure to include the influence of all parameters in the calculations.

$\checkmark \quad$ Due to varied interactions between elements in the system, none of the design methods could cover all these interactions. In this case, a development of finite element model is considered as an effective method to include the influence of all parameters in the design. The results of numerical simulation are supposed to give results close to reality in comparing with the analytical methods.

\section{References}

[1] A. Sakleshpur, M. Madhav, Embankments on Soft Ground: An Overview, 1st International Conference on Foundation and Soft Ground Engineering, Thu Dau Mot University, Binh Duong, Vietnam, 2013, pp. 27-44.

URL https://Ww. researchgate.net/publication/306107953

[2] P. Halder, B. Singh, Soft Soil Response and Behaviour of Piles Under a Geotextile Reinforced Embankment, Indian Geotechnical Conference IGC2016, IIT Madras, Chennai, India, 2016.

URL https://WWW. researchgate.net/publication/329170394 
[3] K. Liu, R. Rowe, Three-dimensional finite element modelling of a full-scale geosynthetic-reinforced, pile-supported embankment, Canadian Geotechnical Journal 52 (12) (2015) pp. 2041-2054.

doi: https ://doi .org/10.1139/cgj-2014-0506

[4] J. Han, L. Yan, J. Yang, Parametric study on geosynthetic- reinforced pile supported embankment, GeoShanghai International Conference, 2006, pp. 255-261.

doi: https ://doi.org/10.1061/40863(195)28

[5] J. Han, A. Gabr, Numerical Analysis of Geosynthetic-Reinforced and PileSupported Earth Platforms over Soft Soil, Journal of Geotechnical and Geoenviromental Engineering 128 (1) (2002) pp. 44-53.

doi: https://doi.org/10.1061/(ASCE)1090-0241(2002)128:1(44)

[6] H. Rathmayer, Piled embankment supported by single pile caps, Istanbul Conference on Soil Mechanics and Foundation, Istanbul, 1975, pp. 283-290.

[7] J. Han, Design and construction of embankments on geosynthetic reinforced platforms supported by piles, Proceeding of 1999 ASCE/ PaDOT Geotechnical Seminar, Central Pennsylvania Section, ASCE and Pennsylvania Department of Transportation, 1999, pp. 66-84.

[8] M. Nuñez, D. Dias, R. Kastner, C. Poilpré, Soft Ground Improved by Rigid Vertical Piles. Experimental and Numerical Study of Two Real Cases in France, 6th Conference of the International Conference on Case Histories in Geotechnical Engineering, Arlington, Virginia, 2008, pp. 40-49.

URL

https://scholarsmine.mst. edu/icchge/6icchge/session@7/40

[9] B. Chevalier, P. Villard, G. Combe, Investigation of Load-Transfer Mechanisms in Geotechnical Earth Structures with Thin Fill Platforms Reinforced by Rigid Inclusions, International Journal of Geomechanic 11 (3) (2011) pp. 239-250.

doi: https ://doi .org/10.1061/(ASCE) GM. 1943-5622.0000083

[10] S.J.M van Eekelen, A. Bezuijen, H.J. Lodder, A.F. van Tol, Model experiments on piled embankments. Part I, Geotextiles and Geomembranes Journal 32 (2012) pp. 69-81.

doi: https://doi.org/10.1016/j.geotexmem.2011.11.002 
[11] S.J.M van Eekelen, A. Bezuijen, A.F. van Tol, Model experiments on piled embankments. Part II, Geotextiles and Geomembranes Journal 32 (2012) pp. 82-94.

doi: https ://doi.org/10.1016/j.geotexmem.2011.11.003

[12] S.J.M van Eekelen, A. Bezuijen, A.F. van Tol, An analytical model for arching in piled embankments, Geotextiles and Geomembranes Journal 39 (2013) pp. 78-102.

doi: https ://doi .org/10.1016/j .geotexmem . 2013.07.005

[13] W. Al-Ani, D. Wanatowski, H. Chan, Numerical Analysis of Piled Embankments on Soft Soils, Geo-Shanghai Conference, 2014, Shanghai, pp. 30-39.

doi: https ://doi.org/10.1061/9780784413401.003

[14] D.F. Fagundes, M.S.S. Almeida et al., Load transfer mechanism and deformation of reinforced piled embankments, Geotextiles and Geomembranes Journal 45 (2) (2017) pp.1-10.

doi: https ://doi.org/10.1016/j.geotexmem.2016.11.002

[15] C. Phutthananon, P. Jongpradist, P. Jamsawang, Influence of cap size and strength on settlements of TDM-piled embankments over soft ground, Marine Georesources \& Geotechnology (2019) pp.1-20.

doi: $h$ ttps ://doi .org/10.1080/1064119X.2019.1613700

[16] P.T. Thanh Truc, L.L. Gia, T. Hino, Valuate the effect of embankment height and pile spacing to the behaviour of the Geosynthetic Reinforced Piled embankment using FEM, NAG2018 conference, University of Technology, Ho Chi Minh City, Vietnam, 2018.

URL https://WWw. researchgate. net/publication/327834113

[17] K. Terzaghi, Theoretical Soil Mechanics, John Wiley \& Sons, Inc, New York, USA, 1943, p. 526.

[18] D. Russell, N. Pierpoint, An assessment of design methods for piled embankments. Ground Engineering 30 (11) (1997) pp. 39-44.

URL https://trid. trb.org/view/476724 
[19] V.A. Guido, J.D. Kneuppel, M.A. Sweeney, Plate loading tests on geogrid reinforced earth slabs. Geosynthetic‘87 Conference 87 (1) (1987) pp.216225.

[20] B. Carlson, Reinforced soil, principles for calculation, Terratema AB, Linköping, Swedish, 1987.

[21] G. Svan $\varnothing$, T. Ilstad et al., Alternative calculation principle for design of piled embankments with base reinforcement, 4th International Conference on Ground Improvement Geosystems, Helsinki, 2000.

URL https://WwW. researchgate.net/publication/327652189

[22] W.J. Hewlett, M.F. Randolph, Analysis of piled embankments, Ground Engineering 22 (3) (1988) pp.12-18.

[23] P. Berthelot, T. Bret et al. Recommendations for the Design, Construction and Control of Rigid Inclusion Ground Improvements. Presses des Ponts, Paris, 2012, p. 316.

[24] BS 8006, Code of Practice for Strengthened /Reinforced Soils and Other Fills, British Standard Institution, London, UK, 2010.

URL http://worldcat.org/isbn/0580242161

[25] BS 8006, Code of Practice for Strengthened /Reinforced Soils and Other Fills, British Standard Institution, London, UK, 1995.

URL https://webstore.ansi.org/standards/bsi/bs80061995

[26] B.K. Low, S.K. Tang, V. Choa, Arching in piled embankments, Journal of Geotechnical Engineering 120 (11) (1994) pp.1917-1938.

[27] P. Ariyarathne, D.S. Liyanapathirana, Review of existing design methods for geosynthetic-reinforced pile-supported embankments, Soils and Foundations 55 (1) (2015) pp.17-34.

doi: https://doi.org/10.1016/j. sandf.2014.12.002

[28] S.J.M. van Eekelen, A. Bezuijen, A.F van Tol, Analysis and modification of the British Standard BS8006 for the design of piled embankments, Geotextiles and Geomembranes Journal 29 (3) (2011) pp.345-359. doi: https ://doi.org/10.1016/j . geotexmem . 2011 . 02 . 001 
[29] R.W. Sarsby, Geosynthetics in civil engineering, Wood head Publishing Limited in association with The Textile Institute, Cambridge, England, 2007, 308p.

URL https://WWW.pdfdrive.com/geosynthetics-in-civilengineering-e185194584.html

[30] H.G. Kempfert, C. Gobel et al., German recommendations for the reinforced embankments on pile-similar elements. Geosynthetics in Civil and Environmental Engineering (2004) pp.697-702. doi: https ://doi.org/10.1007/978-3-540-69313-0_128

[31] The German Geotechnical Society, Recommendations for Design and Analysis of Earth Structures using Geosynthetic Reinforcements - EBGEO, 2st Edition, Munich, Germany, 2012, p. 324.

doi: $h$ ttps ://doi.org/10.1002/9783433600931

[32] S.W. Abusharar, J. JZheng, B.G. Chen, J.H. Yin, A simplified method for analysis of a piled embankment reinforced with geosynthetics, Geotextiles and Geomembranes Journal 27 (1) (2008) pp. 39-52.

doi: https://doi.org/10.1016/j.geotexmem.2008.05.002 